\title{
Disrupted but interactive: How online learning works in the age of a pandemic
}

\author{
A. Anggraeni, S. Putra \& A. Nurhudatiana \\ Bina Nusantara University, Jakarta, Indonesia
}

\begin{abstract}
As universities shift from face-to-face learning to distance learning, the student learning experience has dramatically changed. The classes have moved to online mode, which means that there are changes in terms of how the classes are conducted. Changes also take place in terms of how the interaction happens between the facilitators and the students as well as between the students. This study aims to investigate how different learning factors may contribute to student satisfaction. In total, there are 100 respondents that comprise both undergraduate and Master's students. The findings suggest that only interactivity and course suitability were found to have a positive influence on student satisfaction. These imply that an educational institution needs to design their online class delivery in such a way so that the interaction will be similar to the interaction in offline classes. Moreover, making sure that the courses are suitable to be delivered in an online mode is crucial as well.
\end{abstract}

Keywords: online learning, learner characteristics, learning satisfaction

\section{INTRODUCTION}

Since the beginning of the COVID-19 outbreak, universities around the world began shifting educational activities from physical classrooms to virtual ones. For example, the Chinese Ministry of Education launched the "Disrupted Classes, Undisrupted Learning" initiative, providing flexible online learning to over 270 million students from their homes (Huang et al. 2020).

The flexible learning approach provides learners with choices about where, when, and how learning occurs, by using a range of technologies to support the teaching and learning process (Lee \& McLoughlin 2010). Flexible learning encompasses multi-dimensional aspects, including infrastructure, learning tools, learning resources, teaching and learning methods, services for teachers and students, and cooperation between government, enterprises, and schools (Huang et al. 2020). The unplanned and rapid move to online learning might result in a poor learning experience since students, lecturers, and university staff generally had not been prepared through simulations or practices beforehand.

To the best of the authors' knowledge, there is still very limited research on the student learning experience during the COVID-19 pandemic in Indonesia. The university students in Indonesia underwent a unique experience of having the first three to four weeks of the semester in physical classrooms and suddenly shifted to virtual classrooms for the rest of the semester. This research aims to understand the students' experience during the period and how it affected learning satisfaction. More importantly, as physical distancing measures would continue for months to come, it is very important for educational institution administrators to understand the crucial determinants that would enhance student learning satisfaction during this pandemic. 


\section{LITERATURE REVIEW}

\subsection{Learner characteristics}

Learner characteristics comprise various components, including attitudes toward computers. Attitudes toward computers include students' feelings, opinions, and perceptions toward general computer use, computer-aided instruction, computer programming and technical concepts, social issues related to computer use, and computer history (Aziz \& Hasan 2012).

Aziz \& Hasan (2012) emphasized the role of the user's attitudes and anxiety affect the knowledge of computers among individuals. Computer anxiety has been widely investigated in the literature. Previous studies have noted that personal characteristics of computer users (age, gender, education, etc.) can be the antecedents of computer anxiety. Somebody with computer anxiety may experience negative feelings such as fear of the unknown, frustration, embarrassment, failure, and disappointment and as a result, he or she may avoid using computers (Olatoye 2009). Therefore, it can be hypothesized that:

H1: The more positive a learner's characteristics are, the higher his or her learning satisfaction.

\subsection{Instructor characteristics}

Previtali \& Scarozza (2019) revealed that the teaching style creates a stimulating effect on students' recognition of e-learning. In the context of online learning, there is an ever-pressing need for educators to use the tools of technology to achieve teaching goals, such as implementing the right methods, doing lesson planning and assessments, among other things (van Rensburg 2018). Instructor characteristics were also linked to class size as well as workload, as bigger class sizes and more workload could lead to less positive evaluation of the instructors (Özgüngör 2013).

Instructors in online learning can engage with the students through providing timely and useful responses or feedback to their assignments and projects (Martin et al. 2020). Therefore, it can be hypothesized that:

H2: Instructor characteristics have a positive and significant influence on online learning satisfaction.

\subsection{Course suitability}

Some courses may be suitable to be delivered online; however, some courses which require handson practices may suffer from the lack of interaction. The shift in learning mode has required all courses to be delivered in an online manner, regardless of their suitability. It was found that for online courses, subjects that are assessed by project-based assignments and involve high-level knowledge activities may increase learning effectiveness (Zheng et al. 2020).

Stier \& Schneider (2009) argued that study programs do not have to choose between online and offline learning; rather, the choice should be made based on analysis of the suitability of the courses to be delivered. Courses with assignments and more theoretical components can be suitable for online learning delivery. On the other hand, courses with heavy experiential components are least suited for online delivery (Willett et al. 2019). Hence, it can be hypothesized that:

H3: Course suitability has a significant and positive influence on learning satisfaction.

\subsection{Interactivity}

University learning tends to be collaborative in nature, as students have the opportunity to discuss with others as opposed to pursuing their own learning goals (Koschmann et al. 1996; Yang et al. 2016 in Lin et al. 2018).

Interactivity is considered to be the key to effective learning (Blasco-Arcas et al. 2013). Interactivity can be divided into two types: interactivity with the other students and interactivity with 
the facilitators (Blasco-Arcas et al. 2013). The interaction with fellow students is usually in the form of group discussion, and class participation; these types of activities can improve active and high-order learning (Crouch \& Mazur 2001). Active learning that involves collaboration with other students has been noted to improve students' learning experience (Blasco-Arcas et al. 2013) and possibly student satisfaction. This is due to the possibilities that interaction may enable the students to think critically and look for alternative answers, leading to deeper knowledge processing activity (Blasco-Arcas et al. 2013). Hence, it can be hypothesized that:

H4: The higher the level of interactivity during online learning, the higher the learning satisfaction.

\subsection{Technological factors}

Instructional support that students receive can mostly come from the course instructor and the institutions, but technology can be used to provide support to individual students and instructional contexts (Chen et al. 2010). The tools that are available online to the facilitators and learners can influence the online learning process (Deshwal et al. 2017). A previous study on the experience of online learning through massive open online courses (MOOCs) reported that internet access quality played an important factor in MOOC users' decision to continue participating in online courses. (Nurhudatiana et al. 2019). Therefore, it can be hypothesized that:

H5: Availability of the technological facilities will have a positive influence on learning satisfaction

\subsection{Supporting factors}

Online learning enables the learners to process learning materials based on their individual preferences at any time and from any place; they may select and examine material from a large pool of information (Artino \& Stephens 2009; Narciss et al. 2007). Universities generally provide additional services such as a hotline or email address that students can contact should they encounter any problem during the online learning situation. Pieces of advice, counseling, and other facilities are also provided to improve the students' learning experience. A face-to-face consultation that complements online consultation facilities can also enable students to solve problems that may arise during online learning. Therefore, it can be hypothesized that:

H6: The availability of supporting factors has a positive and significant influence on learning satisfaction.

\section{METHOD}

This research utilizes the quantitative method with survey as the data collection method. The survey was distributed to undergraduate and Master's degree students who learn using an online learning method. There are seven variables investigated in this research: learner characteristics, instructor characteristics, course suitability, interactivity, technological factors, supporting factors, and learning satisfaction.

The data analysis was conducted using PLS SEM software. Construct reliability and validity as well as discriminant validity, were checked based on the Cronbach's Alpha's values, Average Variance Extracted, Composite Reliability, and Fornell-Lackner criterion. All the indicators were found to be valid and reliable.

\section{RESULTS AND DISCUSSIONS}

In total, 118 respondents participated in this study, with 100 usable responses which were further analyzed using PLS SEM software. Out of those 100 respondents, 31 were females $(31 \%), 65$ 
Table 1. Path analysis results.

\begin{tabular}{lccccc}
\hline Dimension & Original sample & Sample mean & Standard deviation & t-statistic & p-value \\
\hline Learner characteristics & 0.070 & 0.100 & 0.084 & 0.834 & 0.405 \\
Instructor characteristics & -0.018 & -0.019 & 0.075 & 0.238 & 0.812 \\
Course suitability & 0.412 & 0.408 & 0.068 & 6.072 & $0.000^{*}$ \\
Interactivity & 0.288 & 0.281 & 0.100 & 2.871 & $0.004^{*}$ \\
Technological factors & 0.082 & 0.076 & 0.076 & 1.084 & 0.279 \\
Supporting factors & 0.124 & 0.120 & 0.091 & 1.358 & 0.279 \\
\hline
\end{tabular}

*significance at p-value 0.05 .

males (61\%), and 4 preferred not to tell their gender. A majority of them are undergraduate students with $6 \%$ being Master's degree students. The respondents come from different majors, including Business Management, Hotel Management, Computer Science, Information System, and Accounting and Finance.

The path analysis results are given in Table 1 . The adjusted $\mathrm{R}$ square of the model is 0.575 . The findings have shown that only course suitability and interactivity have a positive influence on student satisfaction. This is aligned with the studies conducted by Blasco-Arcas et al. (2013) and Chan et al. (2005). For example, interactivity may vary depending on the class dynamics as well as class size. Instructors who are livelier and better at engaging the students may foster better interaction that leads to higher student satisfaction. The nature of the courses may also vary, which means that experiential and non-experiential courses may not fare similarly. The courses with more theoretical elements can be delivered smoothly with fewer adjustments to the existing offline classes. However, courses with more experiential components may need more adjustments to improve student satisfaction during online learning.

\section{CONCLUSIONS AND FUTURE WORK}

The findings have shown that it is important to keep the interactivity in an online learning context as it makes the students more satisfied with their learning process. It is understandable that the respondents in this study may feel that their interactivity was reduced significantly as the institution pivoted to fully online learning mode. This implies that the facilitators would need to encourage interaction between students; either through online discussion, gamification of learning, or other activities that may foster discussion between the students.

To ensure that everyone feels comfortable to participate and contribute to the discussion, an instructor may set some rules that would encourage them to contribute to the class discussion. Interactivity also involves interaction with peers; thus, in the online setting, the students may be divided into several small groups to ease up the discussion process. In addition to that, educational institutions may need to carefully consider the courses that can be delivered online and the ones that are less likely to be delivered online. The consideration may be based on the type of the course (more practical or theoretical), the possibility of using additional means such as software, etc. This research has some room for improvement. For example, mixing both undergraduate and Master degree's students may lead to slight variance in findings, as there are differences in terms of the learning experience and maturity level of these respondents.

\section{REFERENCES}

Artino, A. R. and Stephens, J. M. 2009. Academic motivation and self-regulation: A comparative analysis of undergraduate and graduate students learning online. The Internet and Higher Education, 12(3-4):146-151. doi:10.1016/j.iheduc.2009.02.001 
Blasco-Arcas, L., Buil, I., Hernández-Ortega, B., and Sese, F. J. 2013. Using clickers in class. The role of interactivity, active collaborative learning and engagement in learning performance. Computers and Education, 62:102-110. doi:10.1016/j.compedu.2012.10.019

Cao, C. and Meng, Q. 2020. Exploring personality traits as predictors of English achievement and global competence among Chinese university students: English learning motivation as the moderator. Learning and Individual Differences, 77:101814. doi:10.1016/j.lindif.2019.101814

Chan, Simon C. H., Wan, C. L. J., Chou, S., and Liu, C. 2005. Learning effectiveness in a Web-based virtual learning environment: A learner control perspective. Journal of Computer Assisted Learning, 21(1):65-76. doi:10.1111/j.1365-2729.2005.00114.x

Crouch, C. H. and Mazur, E. 2001. Peer Instruction: Ten years of experience and results. American Journal of Physics, 69(9):970-977. doi:10.1119/1.1374249

Deshwal, P., Trivedi, A., and Himanshi, H. 2017. Online Learning Experience Scale Validation and Its Impact on Learners' Satisfaction. Procedia Computer Science, 112:2455-2462. doi:10.1016/j.procs.2017.08.178

Hamid, M. R., Sami, W., and Sidek, M. H. 2017. Discriminant Validity Assessment: Use of Fornell and Larcker criterion versus HTMT Criterion. Journal of Physics: Conference Series, 890:012163. doi:10. 1088/1742-6596/890/1/012163

Huang, R., Tlili, A., Chang, T., Zhang, X., Nascimbeni, F., and Burgos, D. 2020. Disrupted classes, undisrupted learning during COVID-19 outbreak in China: Application of open educational practices and resources. Smart Learning Environments, 7(1). doi:10.1186/s40561-020-00125-8

Jokisch, M. R., Schmidt, L. I., Doh, M., Marquard, M., and Wahl, H. 2020. The role of internet self-efficacy, innovativeness and technology avoidance in breadth of internet use: Comparing older technology experts and non-experts. Computers in Human Behavior, 111:106408. doi:10.1016/j.chb.2020.106408

Law, K. M., Geng, S., and Li, T. 2019. Student enrollment, motivation and learning performance in a blended learning environment: The mediating effects of social, teaching, and cognitive presence. Computers and Education, 136:1-12. doi:10.1016/j.compedu.2019.02.021

Lee, M. J. and McLoughlin, C. 2010. Emerging technologies in distance education. In G. Veletsianos (Author), Emerging technologies in distance education (pp. 61-87). Edmonton: AU Press.

Lin, H., Yen, W., and Wang, Y. 2018. Investigating the effect of learning method and motivation on learning performance in a business simulation system context: An experimental study. Computers and Education, 127:30-40. doi:10.1016/j.compedu.2018.08.008

Martin, F., Wang, C., and Sadaf, A. 2020. Facilitation Matters: Instructor Perception of Helpfulness of Facilitation Strategies in Online Courses. Online Learning, 24(1). doi:10.24059/olj.v24i1.1980

Narciss, S., Proske, A., and Koerndle, H. 2007. Promoting self-regulated learning in web-based learning environments. Computers in Human Behavior, 23(3):1126-1144. doi:10.1016/j.chb.2006.10.006

Nurhudatiana, A., Anggraeni, A., and Putra, S. 2019. An Exploratory Study of MOOC Adoption in Indonesia. Proceedings of the 2019 5th International Conference on Education and Training Technologies - ICETT 2019. doi: $10.1145 / 3337682.3337690$

Olatoye, R. 2009. Gender Factor in Computer Anxiety, Knowledge and Utilization among Senior Secondary School Students in Ogun State, Nigeria. Gender and Behaviour, 7(2). doi:10.4314/gab.v7i2.48696

Özgüngör, S. 2013. The Relationship Between Instructor and Course Characteristics and Students' Perception of Instructional quality. Procedia - Social and Behavioral Sciences, 93:1324-1328. doi:10.1016/j.sbspro.2013.10.037

Previtali, P. and Scarozza, D. 2019. Blended learning adoption: A case study of one of the oldest universities in Europe. International Journal of Educational Management, 33(5):990-998. doi:10.1108/ijem-07-20180197

Rensburg, E. S. 2018. Effective online teaching and learning practices for undergraduate health sciences students: An integrative review. International Journal of Africa Nursing Sciences, 9:73-80. doi:10.1016/j.ijans.2018.08.004

Willett, J., Brown, C., and Danzy-Bussell, L. A. 2019. An exploratory study: Faculty perceptions of online learning in undergraduate sport management programs. Journal of Hospitality, Leisure, Sport and Tourism Education, 25:100206. doi:10.1016/j.jhlste.2019.100206 